\title{
Direitos, cidadania das mulheres e religião*
}

\author{
Maria José Rosado-Nunes
}

A questão da igualdade dos sexos ocupa, de fato, um lugar não negligenciável na crise da cultura católica em face da modernidade FLORENCE ROCHEFORT, comentando a obra de Émile Poulat, em Zuber (2001)

Just as liberalism challenged the catholic worldview in the nineteenth and early twentieth centuries, feminism is surely a major challenge to Catholic Christianity in the last quarter of the twentieth century. MARY C. SEGERS (1996)

N este texto, pretendo trabal har pressupostos teóricos eal guns dados empíricos da realidade brasileira, referentes às complicadas relações entre elementos da moderna cultura de direitos, as reivindicações e construções teóricas dos feminismos contemporâneos e os ideais e valores do catolicismo. As bases das discussões propostas são parte de uma pesquisa em curso. N um primeiro momento, analiso a contribuição da I greja católica no Brasil, com sua ação pastoral por meio das chamadas $C$ omunidades Eclesiais de Base, as CEBs, para a construção de uma "cultura de direitos". Em seguida, passando ao âmbito teórico, exploro o interminável conflito dessa I greja com os valores modernos que estão na base das reivindicações das mulheres, desde o século XVIII. Finalmente, voltando à realidade socioistórica do movimento de mulheres ${ }^{1}$, trabalho a questão da ampliação do conceito de direitos para nele incluir os recém-denominados "direitos sexuais e direitos

* Este texto é um produto parcial depesquisa em curso apoiada pelo CNPq.

1. U sarei, indiferentemente, "movimento feminista" ou "movimento demulheres", evitando assim a polêmica sus citada por essa distinção, não necessária para a presente discussão. 
2. A expressão "cultura dedireitos" encontra-se em D agnino (2002, p. 12).

3. Há várias obras que tratam daquestão dare lação Igreja/Estado no Brasil. A mais recente édeautoriadeKenneth P. Serbin (2001).

4.Tal silêncio ocorreu especialmente no caso das freiras, cuja históriade efetiva participação na realização do projeto institucional de constituição das CEBs foi fundamental à sua instituição e manutenção. Ver Rosado-N unes (1997). reprodutivos" como um novo, ma non troppo, campo de conflito entre 0 ideário feminista e o ideário católico.

Igreja católica no Brasil e a construção de uma "cultura de direitos" 2

$\mathrm{Na}$ história política do Brasil contemporâneo, há certo consenso nas análises políticas quanto à I greja católica, diferentemente do que ocorreu em outros países da região, ter se destacado como uma das instituições da sociedade civil que integraram as forças de resistência ao regime autoritário militar. Alguns de seus bispos, incluindo o cardeal de São Paulo à época, dom Paulo Evaristo Arns, tornaram-se lideranças reconhecidas da luta democrática pela restauração dos direi tos civis e pelo respeito aos direitos humanos, denunciando as práticas de tortura e os assassinatos cometidos nos porões da ditadura ${ }^{3}$. Essa atuação da I greja foi tanto maisimportantequanto era ela uma das únicas - senão a única - instituições da sociedade civil que podia "dar voz pública" à resistência ao regime militar.

N esse mesmo período, a I greja católica desenvolveu um discurso e uma prática caracterizados como "de esquerda" - a Teologia da Libertação e as Comunidades Eclesiais de Base. Cabe notar que, enquanto na elaboração do discurso teológico prevaleceram os homens, na realização da proposta da formação de comunidades religiosas politicamente comprometidas com os ideais de justiça social, o lugar das mulheres foi proeminente, ainda que muito raramente as análises acadêmicas, aquelas oriundas do interior da mesma I greja e os textos teológicos tenham incorporado esse dado aos estudos dessas comunidades 4 . Foram pesquisadoras reconhecidamentefeministas ou aquelas que tomaram as mulheres das CEBs como objeto de suas pesquisas queinterrogaram esse discurso eessa prática, do ponto de vista de seus efeitos sobre a vida da população feminina das comunidades (cf. Alvarez, 1986, 1990, 1994; D rogus, 1997; Lobo, 1991; M acedo, 1986; M achado, 1996; Rosado-N unes, 1994).

Várias dessas pesqui sas real izadas sobre as mulheres atuantes nas $\mathrm{C}$ omunidades Eclesiais de Base nos anos de vigência da Teologia da Libertação, nas décadas de 1970 e 1980, apontaram para a importância da noção de "direitos". Elas indicam como a afirmação dos direitos sociais enquanto parte inalienável da realização da justiça "querida por Deus" levou uma parcela significativa dessas mulheres a rei vindicar também direitos relativos a questões tratadas como de âmbito estritamente individual, privado. 0 processo dessa "transferência" - da reivindicação de direitos sociaisà reivin- 
dicação de "direitos" no campo privado - é bastante complexo. Para algumas autoras (cf. Lobo, 1991; Rosado-N unes, 1994), foi o cruzamento de matrizes distintas, e até opostas, de pensamento - religiosas e feministas - , possibilitado pela mesma ação da I greja, que propiciou a mulheres das camadas pobres a assunção de uma posição que poderia ser denominada "feminista", ainda que não assim compreendida por todas, no sentido da luta pelo reconhecimento de direitos no âmbito da sexual idade, da reprodução e da domesticidade.

A ação eclesial caracterizou-se, assim, nos anos de 1960 e no período da "abertura", não só pelo enfrentamento do Estado autoritário, mas também por sua contribuição à construção de uma "cultura de direitos", atuando, de al guma maneira, como fator de democratização da sociedade brasileira5. A I greja incorporou a noção de direitos em seus discursos e proposições de ação pastoral e a transmitiu a suas/seus fiéis, dando ênfase aos direitos sociais, relacionados com a idéia de justiça social, e aos direitos individuais, na medida em que era necessário invocá-los a favor de presos políticos. I sso é particularmente importante diante da história política do país, marcada por uma tradição de autoritarismo e domínio de elites conservadoras e da própria I greja católica, historicamente aliada aos grupos de posição política mais conservadora e aos governos en place.

No quadro das preocupações que informam o presente texto, é importante enfatizar neste primeiro momento que a ação eclesial católica nesse período teve relevância política em um campo de difícil assimilação por essa instituição religiosa: o da afirmação das liberdades democráticas e da defesa de direitos individuais, invocados como direitos humanos, ideário devedor da M odernidade 0 cidental. Vinte anos depois da liberalização do regime e da restauração de práticas políticas democráticas no país, a sociedade civil brasileira dotou-se de instrumentos político-sociais adequados para a expressão dos anseios e das necessidades da população, bem como para a reivindicação do respeito aos seus direitos. Reconstrói-se a cidadania, fortal ece-se paulatinamente a sociedade civil, e a tutela da instituição religiosa deixa de ser adequada para a nova situação política do país. 0 campo religioso brasileiro, por sua vez, passa por enormes mudanças, apontando para a diminuição da força hegemônica da I greja católica, que altera o direcionamento de sua política institucional. As CEBs deixam de ser o centro da atuação pastoral, e o discurso teológico da libertação declina em prestígio social e em força religiosa. Tais mudanças não se dão sem que uma crise se instale na instituição.
5.0 reconhecimento da importância dal greja católica para a redemocratização do país não nega a complexidadee a diversidade de fatoresqueinterferiram nesse processo. Q ualquer análise das relações entre a Sociedade $\mathrm{Ci}$ vil, da qual a instituição eclesial é parte, e o Estado deve tomar em conta a multiplicidade das relações políticas heterogêneas em questão. Ver Dagnino (2002). 
6. Fazem partedasestratégias de ação dos grupos da I greja que integram o "projeto libertador", ou a chamada "ala progressista", oschamados "cursos de verão". Trata-se de cursos de grandesproporções, aos quais comparecem em torno de quinhentas pessoasdetodo o Brasil. São organizadospor um centro ecumênico, de direção e predominância católica, a cada ano, no mês de janeiro, em São Paulo. Cobrem o período da "crise", tendo se iniciado ainda na vigência da crença no primado das mudanças estruturais, estendendo-se até 0 momento atual, em que se dá "0 enfraquecimento 'político' intra-institucional dos grupos de esquerda religiosa" (Burity, 1998, p. 10).
Seguindo a análise de Burity (1998), após a predominância de um ativismo religioso de esquerda, expresso basicamente na Teologia da Libertação e nas CEBs, instala-se uma crise e o sentimento de que "o projeto" frustrou-se. U ma das conseqüências éa necessidade de readequação do discurso teológico.

Se este discurso "se adequava" às condições de luta contra a ditadura ou mesmo do socialismo como horizonte geral de mudança histórica (o mais visível sinal do reino de deus), o mesmo não se pode dizer do período aberto pela experiência da democratização e pel os desafios colocados pela hegemonia do neoliberalismo no discurso político e nas políticas estatais (I dem, p. 8).

Entre os elementos que deveriam conduzir à mudança da economia discursiva da teologia, Burity inclui a etnicidade, o cotidiano, a subjetividade, o gênero, o corpo, o prazer, a religiosidade. Tais "temas e corpos", que apontam para uma

[...] hegemonização do "político" pelo "cultural" [...], estiveram no limbo ou foram explicitamente rejeitados pela "segunda geração" da teologia da libertação, que se colocou como tarefa a mais explícita formulação da teologia do político quetomou a problemática do socialismo por horizonte (Idem, p. 9) ${ }^{6}$.

A escolha institucional, por sua vez, diante do quadro de crescentes e rápidas transformações do campo religioso brasileiro, claramente expressas no último censo, de 2002, foi a da competição com as novas manifestações e organizações religiosas pentecostais e neopentecostais. Em lugar das CEBs, a ênfase pastoral passou a concentrar-se nas comunidades carismáticas, de caráter emocional e bastante distintas do modelo anterior, especialmente em relação aos rituais realizados e ao engajamento político dos membros.

\section{Catolicismo e modernidade: o conflito incontornável}

Émile Poulat propõe que a ambição da modernidade de construir, pela primeira vez na história, um consenso universal se expressa na criação do conceito de "direitos do homem" (1986, p. 27). Tal ideologia dos direitos, carregada de paradoxos e limitações, retira seu fundamento do conceito iluminista de "humanidade" efoi forjada "rompendo com osprincípios católicos". A violenta oposição da I greja católica ao conceito de direitos humanos 
no século XIX éabordada por C harles Curran em livro recente sobre a doutrina social da I greja. O s direitos humanos - diz ele - eram identificados com o iluminismo no campo filosófico. $O$ Syllabus dePio IX ea condenação de Leão XIII às liberdades modernasilustram essa perspectiva.

0 movimento das L uzes fundava os direitos humanos na liberdade ena autonomia da pessoa individual, ao que o catolicismo se opunha vigorosamente. A pessoa não é autônoma, precisamente porque os direitos humanos são relacionados com $D$ eus, como também com o próprio mundo [...]. A teologia moral católica insistia nos deveres e não nos direitos (Curran, 2002, p. 215).

N um conceito liberal de sociedade, de humanidade e de mundo, os "direitos humanos" baseiam-se em três pressupostos: "um conceito extensivo e abstrato de 'humanidade', um conceito de direitos, para o qual a 'humanidade' éaúnica condição necessária, ea tomada de consciência do indivíduo como unidade social resultante destes direitos" (Poulat, 1986, p. 28). Segundo Poulat, esses pressupostos subjacentes à teoria liberal dos direitos explicam "o interminável e talvez insuperável conflito - que se repete incessantemente - entre catolicismo e liberalismo. É possível considerar este conflito à luz dos novos problemas acarretados pela bioética: contracepção, aborto, eutanásia e, de modo mais geral, a sexualidade" (I dem, p. 28).

Esse conflito entre catolicismo e liberalismo pode ser visto na forma como o direito se desenvolveu e como o conceito de natureza foi mudando. A lei natural, denominador comum de cristianismo e modernidade, transformou-se radicalmente. "Com a ciência moderna, assim como a própria ciência, a lei moderna repudia o conceito cristão de natureza forjado pelo pensamento escolástico, na esteira deA ristóteles" (I dem, p. 29). Sea basedas idéias cristãs se encontra na afirmação de D eus como causa primeira e fundamento último, o pensamento científico e a lei moderna apóiam-se no contrato social enum certo conceito de razão - o que descarta apelosà divindade. "N este esforço de construção científica e legal emerge um novo ser humano: o indivíduo esua consciência, senhor desi, de seusjuízos edesuas decisões" (Idem, p. 29). 0 "ser humano" nascido da Reforma protestante deveobedecer unicamenteà sua consciência.

Para o cristianismo, toda liberdade é um dom de $D$ eus, não é inerente ao indivíduo e não é fonte de direitos. "Ao contrário, todos os esforços do espírito moderno tenderão a abolir esta arbitrariedade e libertá-la, oferecendo à natureza humana al go que até então dependia de uma ordem supe- 
rior" (Idem, p. 32). Essa transformação, no campo do direito, significou a invenção do indivíduo como

[...] unidade social e seu corolário: "um ser humano equivale a um ser humano". Este princípio da individualidade não só se opôs à ordem social católica, mas também à ordem religiosa. D esenvolveu-se um conflito de direitos: o direito do indivíduo à liberdade de consciência, de opinião e de religião; 0 direito do catolicismo, considerado como religião de Estado, a representar a verdade absoluta e a tirar as que pareciam daí resultar [...]. 0 individualismo liberal destilava atésmo social: uma sociedade leiga não mais precisava de um $D$ eus para guiar-Ihe os passos e manteveo na esfera da vida privada e na intimidade da consciência e da família (Idem, pp. 33-34).

M esmo reconhecendo uma dramática mudança no pensamento católico no século XX, Curran mostra como se manteve essa oposição à afirmação liberal da liberdade individual. $\mathrm{N}$ ão há dúvida de que ocorreu uma importantíssima transformação no século XX, à medida que a doutrina social católica chegou a um maior apreço pela liberdade, dignidade e direitos da pessoa individual. M as, "embora a doutrina social católica tenha aprendido real mente do liberalismo filosófico eda experiência humana, ela não pode e não há de aceitar a compreensão individualista que 0 liberalismo tem da pessoa humana" (C urran, 2002, p. 221).

Essas discussões permitem compreender a manei ra como a I greja católica se manifesta em relação aos direitos das mulheres. A análise do "infindável e, talvez, insuperável" conflito entreidéias liberaise concepções católicas ajuda a entender as tensões entre o catolicismo e as lutas das mulheres por autonomia.

Direitos das mulheres: 0 confronto entre 0 ideário feminista e o ideário católico

A civilização do controle e do medo instaurada pelo cristianismo, associada à repressão do prazer eà suspeita sobre o sexo, é inseparável da desvalorização simbólica e social das mulheres. M esmo se nos lembrarmos de que no matrimônio cristão, instituído no século XII pela I greja, são os noivos que realizam o sacramento, havendo portanto um reconhecimento da capacidade das mulheres tanto quanto dos homens de expressarem sua vontade, a atribuição às mulheres de uma natureza própria cuja "essência" é a maternidade é um continuum no pensamento eclesial. As diferenças bio- 
lógicas, constantemente invocadas, validam a atribui ção das mulheres à esfera doméstica, reafirmando a legitimidade de sua exclusão da esfera pública e reiterando sua inferioridade social e política. "N os primeiros séculos da I greja", interroga M ichelle Perrot,

[...] predomina a representação da mulher como fonte de pecado, da sexualidade como eterna tentação, assim como do casamento como um estado inferior. Em que medida estes dados fundamentais mudaram?É o quese pergunta muitas vezes, diante do rigor das posições atuais da I greja. [...] Por que esta obsessão, e mesmo este ódio da carne, da sexualidade, e esta profunda desconfiança da mulher no cristianismo? D esconfiança que informou toda a cultura ocidental judaico-cristã. Por quea sexualidadeé, hoje, uma linha de defesa e de afirmação da I greja, notadamente por parte de J oão Paulo II? [...] Tudo se passa como se a I greja tivesse investido o sagrado na moral sexual, colocado o sexo no coração do religioso, para responder a esta religião do sexo que invadea sociedade contemporânea (2002, pp. $195,197,198)^{7}$.

Ao analisar a posição desse papa, Patrick Snyder (s.d.) diz que para João Paulo II, a concepção da mulher veiculada pelo movimento feminista nega sua vocação à maternidade, que foi inscrita em seu corpo pelo próprio Criador. 0 papa considera que um dos erros do feminismo ocidental éjustamenterecusar essa determinação corporal que define as mulheres como mães e esposas. M ary Segers, em estudo sobre o pensamento católico a respeito das mulheres, analisa uma Carta Apostólica do mesmo papa, "M ulieris D ignitatem", de 1988. N esse documento repete-se a ênfase nessa visão tradicional das mulheres como mães, apontando a criação e o cuidado como "qualidades femininas especiais" (1996, p. 597). Segers chega à conclusão de que, no pensamento papal, "as mulheres encontram sua dignidade e vocação principalmente por meio do casamento e da maternidade [...]. A linguagem do papa sugere uma mistificação da maternidade e uma expectativa exagerada em relação à sensibilidade materna" (Idem, p. 600).

$M$ artine Sevegrand mostra como o pensamento de João Paulo II sobrea sexualidade confirma a condenação dos métodos contraceptivos contida no famoso documento de Paulo VI, H umanae Vitae, e remete a doutrina da I greja à verdade revelada eà natureza da pessoa humana. A autora cita João Paulo II: "[...] a norma ética [da H umanaeV itae] não éuma doutrina inven-
7.Este texto, assim como outros cujos originais são franceses ou ingleses, foi traduzido pelaautoradesteartigo. Ver também o interessante artigo de Claude Langlois(1997). 
tada pelo homem: foi inscrita pela mão criadora de $D$ eus na natureza mesma da pessoa humana, efoi confirmada na Revelação" (2002, p. 224).

Para outro autor, Charles Curran,

[...] a perspectiva masculina aflora em quase todos os documentos da doutrina social católica. A mulher tende a ser invisível nos documentos mais antigos, exceto quando sefala defamília. D entro da família, porém, os documentos maisantigos estabelecem claramente e exaltam a posição subordinada da mulher. M esmo hoje o papel da muIher éprimariamenteo de mãee educadora dos próprios filhos no lar (2002, p. 94).

Essa concep ção biologizante das mul heres como esposas e mães que prevalece na I greja estabelece um lugar e um papel social, político e simbólico diferenciado e hierarquizado para mulheres e homens. $N$ ão apenas forma a base de sustentação do poder eclesiástico, hierárquico e masculino, mas também funda um modelo de relação entre os sexos, independente das vontades individuais porque referida a uma "ordem natural" dada por D eus, fundada na biologia, imutável. Estabelecem-se, assim, os parâmetros de relações familiares, em que a autoridade é hierárquica e patriarcal.

"Feministas e especialistas em estudos das mulheres nas religiões criticaram o cristianismo católico", diz Segers, por sua concepção tradicional das mulheres como esposas e mães, em primeiro lugar, por sua negação da voz das mulheres "na vida da I greja, por sua longa história de medo e desconfiança das mulheres. C omo uma força cultural na história ocidental, a I gre ja, em sua maior parte, excluiu as mulheres da educação, ou educou-as seletivamente para papéis sociais na vida doméstica" (1996, p. 596).

0 ideário católico sobre as mulheres continua, assim, a diferir radicalmente daquele elaborado pelas mulheres, em especial pelas feministas, no correr das últimas décadas, ao menos. E entra em conflito com as reivindicações feitas por elas, invocando seus direitos, relativos a todos os âmbitos de suas vidas - privada e pública. A concepção das mulheres que a I greja propõe, vinculada definitivamente à realização real ou espiritual da maternidade, define-as como seres para outros. As características atribuídas a uma suposta "natureza feminina", sensibilidade, delicadeza, capacidade de doarse e de perdoar, numa escala que vai sempre delas para alguém, contrapõem-se frontalmente à afirmação do desejo de ser para si mesma que as mulheres expressam. Em pesquisa feita junto às Comunidades de Base da Zona Leste de São Paulo, no final dos anos de 1980, a pergunta repetida pelaslíderes era: "E eu, como mulher, como équefico?" (cf. Rosado-N unes, 
1994). Tal pergunta era reiterada no contexto de um discurso que questionava a I greja, que reconhecia as mulheres constantemente como esposas e mães, fosse no ambiente familiar, fosse no da comunidade, como "mães espirituais", responsáveis pelo grupo.

Q uando essas mulheres reconhecem seu direito a uma realização pessoal que não passa pela "doação aos outros", mas pela busca de uma felicidade referida asi mesmas, elas secontrapõem ao modelo cristão quedefine o bem e o mal. Recusam o gozo postergado, resultado do sacrifício assumido como passagem obrigatória. "M as a gente, enquanto mulher, qual éa al egria quea gente tem?". Elas querem ser felizes aqui e agora. "N a igreja você aprende quetem quetrabalhar pra D eus, vocêtem quesedoar para os outros. M as [a I greja] não ensina quea mulher também tem que sedoar parasi mesma, que ela tem que pensar nela" (Rosado-N unes, 1994, p. 192). A matriz dessa forma de pensar é totalmente moderna e compatível com o feminismo. D anièle H ervieu-Léger (2003) chama a atenção para essas representações de si, para a afirmação da necessidade de realização pessoal, distantes da cultura católica e que se impõem sempre mais fortemente nas sociedades contemporâneas, como parte dos direitos de cada pessoa.

Se esse éum ponto nuclear no embate do feminismo com a I greja católica - a representação de si como sujeito autônomo, dotado de direitos individuais inalienáveis - , a expressão mais acabada desse conflito se dá na proposição contemporânea dos chamados "direitos sexuais e direitos reprodutivos". Reivindicar o sexo ea reprodução como do campo dos direitos, e, portanto, da política, retira-os do lugar da obediência às leis da natureza dadas por D eus - e controladas pelas normas morais eclesiásticas para colocá-los no campo da realização da liberdade individual. Essa é uma revolução fundamental, na medida em queabole a al usão dessas áreas cruciais da vida humana a algo fora delas mesmas, transcendente, para situá-las na área da aplicação dos direitos. A maternidade, locus tradicional da definição do que seja a essência feminina, torna-se objeto de escolha, de decisão individual, deixando de ser o destino real ou simbólico de todas as mulheres.

M aria Betânia Ávila (2005, pp. 17-27) acentua a novidade representada pela proposição dos direitos sexuais e dos direitos reprodutivos, exatamente porque se referem a campos considerados al heios à real ização da democracia e da cidadania. D efinir direitos, criar novos campos de legalidade é participar do jogo democrático, da reinvenção constante da vida em sociedade. Por isso tais direitos configuram-se como parte da real ização do processo de democratização da vida social, de uma forma inusitada, inédi- 
8. N essa linha de pensamento, vale lembrar a discussão do contrato social pela cientista política Carole Pateman, em seu livro publicado há alguns anos no Brasil, 0 contrato se xual (1993). ta historicamente, uma vez que incorporam questões sem as quais as muIheres não podem realizar de maneira plena sua inserção na vida políticå. São, por isso, um campo de invenção e de liberdade, "uma grande ousadia e um grande desafio". Para M aria Betânia Ávila, a busca por legalidade no campo da sexualidade e da reprodução guarda "um sentido revolucionário ou transformador", contraria a lógica do controle, da repressão e da interdição vigentes nesses campos. Inclusive porque - eisso não éde menor importância - são os próprios sujeitos que inventam esses direitos, esse novo campo de legalidade.

Para D anièle H ervieu-Léger (2003-2004, pp. 1-2), a chave dessa revolução está na liberalização da contracepção, nos anos de 1960 e 1970, por causa da afirmação de autonomia que permite às mulheres. Retomando a proposição clássica da sociologia da religião, pelo olhar deM arx, D urkheim, Weber e Simmel, do dépérissement da religião no contexto da emergência histórica da modernidade, ela explica teoricamente esse processo, por três elementos: o primeiro, a desqualificação das explicações religiosas do mundo, em particular do mundo natural, pelo fim das referências às grandes cosmologias; 0 outro, a separação das diferentes esferas da atividade social o político, o econômico, o cultural -, que relega as religiões a uma esfera própria, particular: elas perdem sua capacidade englobante, de articular 0 conjunto da sociedade; e, finalmente, o que ela considera, talvez, o elemento mais importante, a grandeza das sociedades modernas, a afirmação da autonomia do sujeito, a construção da capacidade de definir coletivamente as regras da vida social. E, porque dotados de razão, sujeitos capazes de determinar para si mesmos o que é o bem e o que é o mal. "Esta autonomia coloca em questão, demaneira radical, a heteronomia deleis, de princípios, que se imporiam desde toda a eternidade, de forma transcendente. Esta saída política da religião está exatamente no centro do processo mesmo de elaboração da modernidade" (I dem, p. 1).

Ao discutir a compreensão sociológica do conceito weberiano de secularização, componente do processo modernizador das sociedades ocidentais cristãs, Antônio Flávio Pierucci (1997) encerra seu argumento falando de sexo. Ele faz referência a outro sociólogo, Bryan Turner, que propõe o controle da sexualidade e da reprodução como função básica da religião. Pierucci comenta, então, o fato contemporâneo do decréscimo

[...] da importância da família e do sistema de progenitura para a acumulação e a reprodução do capital, que dissolve no ar o atrativo da recompensa para uma con- 
duta sexual pautada segundo os padrões da norma moral religiosa, inclusive para as mulheres. [...] 0 imperativo da restrição sexual em chave religiosa começa a não fazer sentido quando deixam de estar em jogo, no sexo, a reprodução da espécie e a transmissão da riqueza.

O s "'prazeres da cama' sem propósitos reprodutivos" são indicadores maiores da revolução em curso, desse processo secularizador radical em que "o prazer sexual passa a ser gozado por 'corpos seculares' autonomizados do dever de procriar" (Idem, pp. 116-117).

Essa revolução que significa a autonomia dos sujeitos em relação à própria vida contrapõe-se às tentativas de controle pela I greja dos corpos e dos sexos, fazendo seu discurso sofrer uma crise de plausibilidade sem precedentes, na avaliação de H ervieu-Léger. Para a I greja, as questões relativas à sexual idade eà reprodução relevam da ordem da natureza, são questões que se situam fora do político, não sendo, portanto, objeto de "direitos". E quando busca interferir nas legislações nacionais nesses campos - uniões homossexuais, aborto, pesquisa com células embrionárias, eutanásia e outros - ela não o faz em nome do debate democrático que permite o confronto de opiniões diversas. N ão há "opinião" nessas áreas. É em nome da competência que Ihe foi outorgada por direito divino que ela dá sua palavra autorizada e intenta estendêla a toda a sociedade, uma vez que é a própria natureza do que é humano o que está em jogo. Trata-se de questões que se situam para além do direito de intervenção dos seres humanos, que escapam à capacidade de decisão das pessoas, pois encontram resposta em uma ordem transcendente sobre a qual não se pode pretender qualquer controle. 0 u trata-se, pelo menos, de situações em que a intervenção humana é extremamente restrita, restrições que devem ser definidas em função do respeito às leis divinas das quais a I greja se propõe guardiã.

N esse sentido, o reconhecimento da autonomia dos indivíduos - em especial "dasindivíduas" - nacondução desuavida afetiva e sexual permanece para o catolicismo um tema proibido: o sexo, la part maudite, diz o título de recente artigo já citado de $\mathrm{M}$ ichelle Perrot, sobre religião e sexualidade. "A recusa de uma sexualidade/ prazer, assimilada ao pecado, e mesmo o pecado por excelência, me parece quase fundadora do cristianismo, em todo o caso, com os Padres da I greja, especialmente Agostinho e Jerônimo, que exprimem uma viva repugnância pelo comércio carnal" (Perrot, 2002, p. 193).

$\mathrm{N}$ ão é difícil vislumbrar os embates com o pensamento feminista. H ervieu-Léger lembra queas mulheres são as primeirasa experienciar a natureza 
não maiscomo umaordem. I sso éuma mudança profunda, àqual aspesquisas fazem pouca ou nenhuma referência. Essa experiência, diz a autora,

[... em poucos anos, arrancou uma ou duas gerações de mulheres, ainda socializadas em um catolicismo da submissão (ao padre, ao marido, a D eus eà natureza), a uma concepção - no entanto profundamente interiorizada - do inelutável do seu destino de mulheres, destinadas a gravidezes sucessivas ou a correr riscos pessoais consideráveis para escapar a elas. A desqualificação do discurso católico hoje, em matéria de sexual idade e de procriação, tem sua origem mais profunda nesse abalo sísmico invisível (2003, p. 250).

Esse o significado, em termos de mudança cultural e política, de se tratar sexo e reprodução no registro dos direitos e da cidadania, enão da submissão à natureza. A reivindicação feminista de lidar com a sexualidade e a reprodução, e com o reconhecimento público de uniões homossexuais, não no registro dos "males da condição humana", da compaixão e do acolhimento das pecadoras - sem admitir o pecado - , mas no registro dos "direitos", desloca radicalmente a questão. $N$ ão se trata mais da "atenção às pessoas", mas do sentido da igualdade e da justiça.

Feminismo e catolicismo entram, então, na arena do debate público, em campos discursivos contrários. "As concepções católicas estão no sentido exatamenteoposto à construção feminista do campo da reprodução como campo de direitos e de realização da cidadania, especialmente das mulheres" (Zurutuza, 2001, p. 193).

0 feminismo propõe-se a afirmar os direitos e as liberdades individuais proclamando que as mulheres, como sujeitos sociais, são cidadãs, com 0 direito de interferir na esfera política da sociedade, e, como "indivíduas", têm o direito de controlar sua sexualidade e sua capacidade reprodutiva, condição sinequa non da realização de sua autonomia. No campo dos direitos sexuais e dos direitos reprodutivos, a afirmação da autonomia individual propõe-se como ponto fundamental do exercício da liberdadee como inspiração básica para as disputas na área da legislação.

As discussões referidas neste texto remetem, assim, à análise do "infindável e, talvez, insuperável" conflito entre idéias liberais e concepções cristãs. Recentemente, o Vaticano lançou um novo documento, desta vez sobre

9. Congrégation pour la Doctrine de la Foi (2004). o feminismo ${ }^{9}$. Sua visão negativa sobre o movimento suscitou inúmeras reações de feministas, inclusive católicas. 0 pronunciamento da I greja não traz novidades, reiterando sua posição, referida acima. 0 que importa aqui 
não é tanto essa reafirmação ou as reações que suscita, como o reconhecimento das profundas rupturas que revela, não só em relação ao feminismo, mas à cultura moderna. E voltamos, aqui, ao núcleo da proposição inicial que o presente texto se propunha levantar.

\section{Referências Bibliográficas}

Alvarez, SoniaE. (1986), Thepolitics of gender in Latin America: comparativeperspectives on women in Brazilian transition to democracy. Tese, mimeo.

. (1990), “Women's participation in the Brazilian 'people's church': a critical appraisal". Feminist Studies, 16 (2): 381-409, Summer.

. (1994), “La (trans)formación del(los) feminismo(s) y la política de género en la democratización del Brasil". In: LEON, M agdalena (org.), M ujeresy participación política, avances y desafíos en América Latina. Bogotá, T/m., pp. 227-289.

ÁviLA, M aria Betânia. (2005), “Liberdade e legalidade: uma relação dialética”. In: Ávila, M aria Betânia, Portella, Ana Paula \& Ferreira, Verônica (orgs.), N ovas legalidades e democratização da vida social: família, sexualidade e aborto. Rio de Janeiro, G aramond, pp. 17-27.

Burity, Joanildo A. (1998), "Religião, mercado e política: tolerância, conformismo e ativismo religioso". Trabalho apresentado na VIII Jornadas sobre Alternativas Religiosas na América Latina, São Paulo, mimeo.

Congrégation pour la Doctrine de la Foi (Joseph Ratzinger). (2004), Lettre aux Évêques de l'Église catholique sur la collaboration de l'homme et de la femme dans l'Église et dansle monde, 31 mai 2004.

CuRran, CharlesE. (2002), Catholic social teaching: a historical, theological and ethical analysis. Washington, Georgetown University Press.

D AG nin o, Evelina (org.). (2002), Soci edade civil e espaços públicosno Brasil. São Paulo, Paz eTerra.

Drogus, Carol Ann. (1997), Women, religion and social change in Brazil's popular church. N otre D ame, Indiana, U niversity of N otre D ame Press.

H ervieu-LÉGer, D anièle. (2003-2004), "Approches de la sociologie religieuse". Séminaire Sectes et Laïcité, pp. 1-8.

. (2003), Catholicisme, la fin d'un monde. Paris, Bayard.

LAN GLoIs, Claude. (1997), “Faire I'histoire du catholicisme: I'exemple de la théologie moraleà l'époque contemporaine". In: Jo n C H ERAY, Jean (dir.), Approches scientifiques des faits religi eux. Paris, Beauchesne, pp.105-121.

Lo o o, Elisabeth Souza. (1991), A classe operária tem dois sexos: trabalho, dominação e resistência. São Paulo, Brasiliense. 
M ACed o, Carmen Cinira. (1986), Tempo de gênesis. o povo das Comunidades de Base. São Paulo, Brasiliense.

M ACH AD O, M . das D ores C ampos. (1996), Cari smáti cos e pentecostais: adesão religi osa na effera familiar. Campinas, Autores Associados/Anpocs.

Pateman, C arole. (1993), 0 contrato sexual. Rio de Janeiro, Paz eTerra.

Perrot, M ichelle. (2002), "Église, sexe et genre: la part maudite". In: M aitre, Jacques \& M ICHelat, Guy (orgs.), Religion et sexualité. Paris, L'H armattan, pp. 193-200. Pieruccl, Antônio Flávio. (1997), "A propósito do auto-engano em sociologia da religião". N ovos Estudos Cebrap, São Paulo, pp. 99-117.

Pou Lat, Emile. (1986), Lesdiscours sur lesdroitsdel'homme: sesparadoxeset ses contraintes, extrait. Actes de la III éme Recontre of $M$ an: its Paradoxes and Limits. Tunis, Centre D 'Etudes et Recherches E conomiques et Sociales.

Rosad o-N unes, M . J. F. (1994), "D e mulheres, sexo e igreja: uma pesquisa e muitas interrogações". In: CostA, Albertina de 0 \& A A AD O, T. (orgs.), Alternativas escassas: saúde, sexualidade e reprodução na América Latina. São Paulo/R io de Janeiro, Prodir/FCC/Editora 34, pp. 175-203. . (1997), "Freiras no Brasil". In: D el Prio Re, M ary (org.), H istória das mulheres no Brasil. São Paulo, Contexto/Unesp, pp. 482-509.

Segers, M ary C . (1996), "Feminism, liberalism, and catholicism". In: Curran, Charles E., Farley, M argaret A. \& M cCormick S. J., Richard A. Feminist ethics and the catholic moral tradition: readingsin moral theology. N ova York/M ahwah, $\mathrm{N}$ J, Paulist Press (série R eading in M oral Theology, n. 9).

Serbin, Kenneth P. (2001), D iálogos na sombra, bispos e militares, tortura e justiça social na ditadura. São Paulo, Companhia das Letras.

Sevegrand, M artine. (2002), "Jean Paul II et la sexualité". In: Maltre, Jacques \& M Ichelat, Guy (orgs.), Religion et sexualité. Paris, L'H armattan, pp. 217-228.

SNYDER, Patrick. (s.d.), "Le féminismeselon Jean-Paul II: I'impasse du déterminisme”.

Disponível no site www.wlu.ca/press/journals/sr/issues/29_3/snyder.shtml.

Zuber, Valentine (org.). (2001), Émile Poulat: un objet descience, lecatholicisme. Lonrai, Bayard.

Zurutuza, Cristina. (2001), "Para uma convenção interamericana pelos direitos sexuais e reprodutivos". In: O LIVEIRA, M aria Coleta $\&$ Roch A, M aria I sabel Baltazar da (orgs.), Saúde reprodutiva na effera pública e política na América Latina. C ampinas, Editora da Unicamp/N epo, pp. 187-207. 


\section{Resumo}

Direitos, cidadania das mulheres e religião

0 texto trabal ha as complexas relações entre elementos da moderna cultura de direitos, as proposições políticas dos feminismos contemporâneos e os ideais e valores do catolicismo. N um primeiro momento, analisa-se a contribuição da I greja católica no Brasil para a construção de uma certa "cultura de direitos", nos anos de 1960-1980, por meio das chamadas Comunidades E clesiais de Base, as CEBs. No âmbito teórico, explora-se o interminável conflito dessa I greja com os valores modernos que estão na base das reivindicações das mulheres, desde o século XVIII. Finalmente, voltando à realidade socioistórica do movimento de mulheres, aborda-se a questão da ampliação do conceito de direitos pela inclusão dos recém-denominados "direitos sexuais e direitos reprodutivos", como um novo, ma non troppo, campo de conflito entre o ideário feminista e o ideário católico.

Palavras-chave: I greja católica; Feminismo; Valores modernos; D ireitos sexuais; D ireitos reprodutivos.

\section{Abstract}

Rights, women's citizenship and religion

The text examines the complex relations between elements of modern culture of rights, the political proposals of contemporary feminists and the ideals and values of $C$ atholicism. In the first part, the article analyzes the contribution of the $\mathrm{C}$ atholic $\mathrm{C}$ hurch in Brazil in constructing a certain 'rights culture,' during the 1960s, 70s and 80s, through the so-called 'Base Ecclesiastical Communities' - the CEBs. At the theoretical level, I explore the interminable conflict between the $\mathrm{C}$ atholic $\mathrm{C}$ hurch and the modern values that have formed the base of women's demands since the $18^{\text {th }}$ century. Finally, returning to the sociohistorical reality of the women's movement, I approach the question of extending the concept of rights to include the recently emergent 'sexual and reproductive rights,' as a new, ma non troppo, field of conflict between feminist and $\mathrm{C}$ atholic ideas.

Keywords: Catholic C hurch; Feminism; M odern Values; Sexual Rights; Reproductive Rights.

Texto recebido e aprovado em 18/8/2008.

M aria José Rosado$\mathrm{N}$ unes é doutora em Ciências Sociais pela École des $\mathrm{H}$ autes Études, Paris, professora da pós-graduação em Ciências da Religião da PU C-São Paulo e pesquisadora do CN Pq. E-mail: mjrosado@ter ra.com.br. 